contributors are specialists of high scientific standing in the United States, Germany, Great Britain, Canada, Peru, Australia, The Netherlands and Israel. The book, of nearly a thousand pages, commences with a review of the physical, chemical, air pollution and extra-terrestrial factors of the atmosphere and the methods used in assessing their effects on the living organism. Part 4, comprising nearly half the book, entitled "The Effect of Weather, Climate and Season on Man", deals in considerable detail with the meteorological influences on the human being and his semi-artificial living conditions in health and disease. Shorter chapters follow diseussing effects on animals and insects, and Part 6 deals with the microclimate of space vehicles.

The final contribution is of the highest importance; written by Prof. F. Sargent of the University of Mllinois, it discusses the necessity and the organization of graduate training in human biometeorology. The urgent need for rapid advances in scientific fields involving two or more disciplines is such that the basic principles stated herein deserve wide recognition. The young scientist must be given sound training in one main science followed by a firm working knowledge in the interdisciplinary régime. In addition he must be able to work as a member of a team so that specialized training and ability can be combined to solve a problem which is of a multiple scientific nature. Most important of all, a student must learn to be able to understand and interpret complex interrelated facts. It must clearly be understood that advances in sciences are not made by the simple collection of endless data, but by the brains of the men who are capable of perceiving the new relationships which can justifiably be deduced from such facts.

The last part of the book consists of a very helpful bibliography of more than 4,000 entries. The very volume of diverse contributions scattered throughout the scientific journals of the world explains why a book of this nature meets a real need. As the author says in his "Retrospect", biometeorologists still have a long way to go before they can solve all the important problems and fully explain the various observations made. Nevertheless, the publication of this volume can truly be regarded as a significant step forward on the road towards increased reliable, useful knowledge.

The printing and presentation are good; the author deserves our thanks for his work and our admiration for his energy and devotion to his aims. His last sentence gives us the clue as to how this can come about-." It is this deeper understanding of the continuous interaction between the living and non-living worlds, which makes biometeorology one of the most fascinating and promising border sciences of the twentioth century".

L. P. SMrTH

\section{THE PRIMARY WORKING GROUP}

\section{Organizational Choice \\ Capabilities of Groups at the Coal Face Under Changing Techniques-The Loss, Re-Discovery and Transformation of a Work Tradition. By E. L. Trist. G. W. Higgin, H. Murray and A. B. Pollock. Pp. $x v+332$. (London: Tavistock Publications (1959), Ltd., 1963.) 48s. net.}

$\mathrm{N}$ most low-soam coal-mining areas threo main types of 1 mining co-exist: the traditional system of singloplace working; a convontional system involving the cutting or hewing of longwalls and hand-filling the coal on conveyors; and the attack on longwalls by a composite group with a much higher level of mechanization.

In the single-place system the key-figure is the multiskilled self-supervising face-worker to whom the deputy or foreman stands more in the role of service agent than that of supervisor. Tho face-worker graduates to this position after years of working on supporting jobs and when he has established his right to the commanding position. Under the conventional system a distinct division of labour emerges where specialized tasks are carried out by a number of groups of varying size. Each group has separate pay-notes and its own mores, while inter-group rivalry and some hostility are not infrequent. Co-ordination and control come directly from management.

With the composite longwall system of working the difficulties arising from over-spocialized work roles, segregated task groups and lack of group cohesion are successfully overcome. There is a common pay-note with an equally shared bonus. The working group itself allocates men to shifts and jobs and the result is a multiskilled commando-like force where all suffer financially if any work is neglected.

Organizational Choice is a long-term study by members of the Tavistock Institute of Human Relations, which describes, inter alia, investigations into the effects on productivity of the single place, conventional longwall and composite longwall systems of working. The conclusions are not unexpected, and, in a truly fascinating way, Trist and his fellow-authors show that where the activitios of a primary working group can be planned and controlled by its own members, the only barriers to productivity are those set by physical limitations in man and the environment. Over a period of two years, the composite group showed itself not only capable of functioning as a "self-regulating, self-developing social organism", but also able to maintain itself at a high level of productivity throughout the whole period. Even more important was that, at the end of the time, the groups were still growing in their capacity to adapt to changes in their task environment and to satisfy the needs of their members. What is more significant, however, is that the composite method of working under a fully mechanized system is but a return to the traditional 'butty' system common in coal-mines before the advent of mechanization. The wheel has turned almost a full cycle and these investigations show that the ruthless breaking down of jobs without regard to human need and dignity leads only to destructive frustration and a low level of productivity, which is the accompaniment of poor individual and group morale.

Apart from a spontaneously generated jargon which characterizes so many Tavistock Institute publications, Organizational Choice is a well-written description of a not undramatic story. The text unfolds to show a clear de. sign, and this is supported by some illuminating tables and diagrams. General conclusions of importance are developed from the specific findings, and all National Coal Board officials should see that the authors' plea for a machinecentred work culture to replace the existing manual work culture could represent the birth of a now attitude to work and workers in the coal-mines. The idea of group training of work-groups rather than individuals also has much to commend it. It is perhaps unfortunate that details of the present-day pay and incentive schemes have not been included if only to enable responsible management and Trade Union officials to persuade more recalcitrant colleagues that the benefits to the men are not only intangible.

So valuable is the book, however, that one wonders whether the authors are doing justice to themselves and their collaborators. Their conclusions should be within the reach of all supervisors and workers in tho coal-fields of Britain and elsewhere. Could their account be turned into film? They might also have indicated other industries and organizations where their findings might have validity. Metal-making, rolling and forging? Oil and chemicals? Rotail storos? Tho approach described in this book and the conclusions arrived at by Trist and his colleagues should also form the basis for case-historins wherover managers and suporvisors are boing trained.

T. H. HAWEINS 